\title{
Integração Saúde e Educação: Contribuições da Psicologia para a Formação de Educadores de uma Cre- che em Sexualidade Infantil
}

Integrating Health and Education: Psychology's Contributions to the Training of Educators from a Daycare Center in Childhood Sexuality Integración Salud y Educación: Contribuciones de la Psicología para la Formación de Educadores de una Guardería en Sexualidad Infantil

Adriane Costa e Rocha Ciaffone, Psicóloga cursando especialização em Terapia Relacional Sistêmica no Instituto Familiare, Florianópolis - SC

Marivete Gesser,

Doutora em Psicologia pela Universidade Federal de Santa Catarina

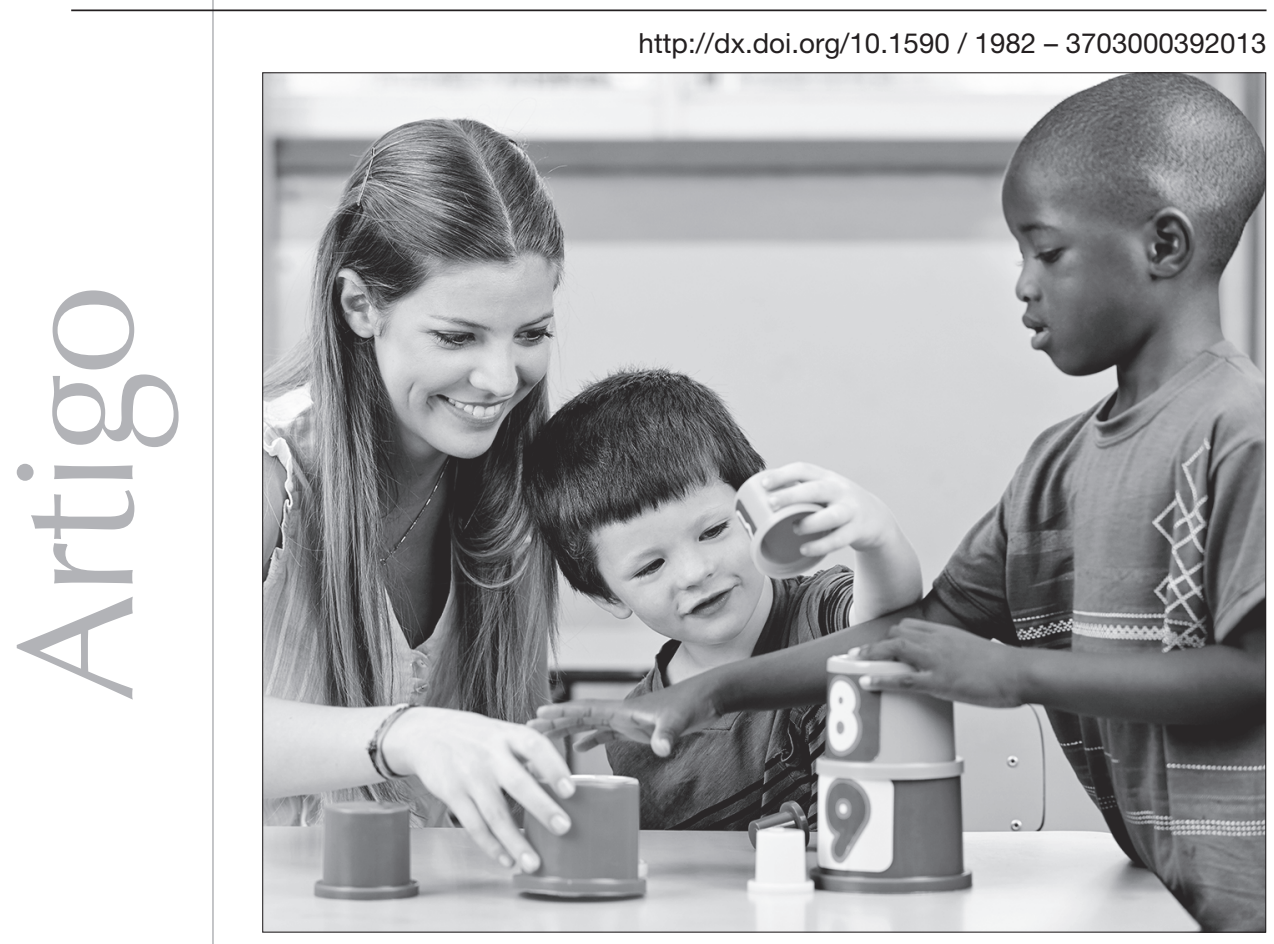


Resumo: Um dos grandes desafios para os educadores que atuam em creches é o de lidar com as expressões da sexualidade no contexto escolar. Os discursos higienistas, morais e religiosos ainda constituem a significação da sexualidade como um fenômeno ligado ao mundo adulto e à reprodução. $\mathrm{O}$ artigo ora apresentado é um relato de experiência de formação em serviço de educadores de uma creche. O trabalho foi realizado por integrantes do PET Saúde da Família em uma creche inserida no território de abrangência onde a equipe atuava. Após a identificação das necessidades, foram realizadas sete oficinas que tiveram como principal referencial teóricometodológico a metodologia de Círculos de Cultura. Os resultados evidenciaram que, a partir do trabalho realizado, os professores conseguiram se instrumentalizar para lidar de forma mais potencializadora dos direitos humanos com as expressões de sexualidade na infância, bem como para atender os pais em suas dúvidas relacionadas ao tema.

Palavras-chave: Educadores. Desenvolvimento psicossexual. Saúde da Família. Programa saúde da família

Abstract: One of the greatest challenges for educators who work in daycare centers is to deal with the expressions of sexuality a school context. The moral, religious, and hygienists discourses still constitute the meaning of sexuality as a phenomenon linked to the adult world and to reproduction. The article here presented is a case study of in-service training of educators from a daycare center. The work was carried out by members of the Family Health Program of Education Through Work (PET Saúde da Família) at a daycare inserted in the area covered where by the team. After identifying the needs, seven workshops were held whose theoretical-methodological background was Culture Circles (Círculos de Cultura). The results showed that, based on the work, the teachers managed to learn mechanisms for dealing with greater regards to human rights with expressions of childhood sexuality, as well as guiding the parents in their questions related to the topic.

Keywords: Educators. Psychosexual development. Family Health. Family health program

Resumen: Uno de los grandes desafíos para los educadores que actúan en guarderías es el de enfrentar las expresiones de la sexualidad en el contexto escolar. Los discursos higienistas, morales y religiosos todavía constituyen la significación de la sexualidad como un fenómeno relacionado al mundo adulto y a la reproducción. El artículo ahora presentado es un relato de experiencia de formación en servicio de educadores de una guardería. El trabajo fue realizado por integrantes del PET Salud de la Familia en una guardería inserida en el territorio de influencia donde el equipo actuaba. Después de la identificación de las necesidades, fueron realizados siete talleres que tuvieron como principal referencial teórico-metodológico la metodología de Círculos de Cultura. Los resultados evidenciaron que, a partir del trabajo realizado, los profesores consiguieron instrumentalizarse para tratar de forma más potenciadora de los derechos humanos con las expresiones de sexualidad en la infancia, así como para atender a los padres en sus dudas relacionadas al tema.

Palabras clave: Educadores. Desarrollo psicosexual. Salud de la Familia. Programa de salud familiar 
O presente trabalho relata uma experiência de formação de educadores sobre o tema sexualidade infantil, destinada a profissionais que atuam em uma creche de um município do sul do Brasil. Tal experiência foi realizada por um grupo de acadêmicos do curso de Psicologia da Universidade Federal de Santa Catarina (UFSC) com a supervisão pedagógica de um professor da mesma área. O trabalho foi solicitado pelos próprios educadores da creche e o objetivo da formação foi o de instrumentalizá-los a lidarem com expressões da sexualidade na infância. Os documentos norteadores foram a Proposta Curricular de Santa Catarina (2008), o Caderno de Orientação Sexual dos Parâmetros Curriculares Nacionais (1997) e o Programa Saúde na Escola (instituído pelo Decreto Presidencial e Interministerial $\mathrm{n}$ o 6.286 de 2007).

O trabalho realizado na creche teve vinculação com um Centro de Saúde (CS) do município, via Programa de Educação pelo Trabalho para a Saúde/Saúde da Família - PET Saúde/SF - instituído pela Portaria Conjunta no 2 (2010). Conforme será explicitado adiante, a elaboração dos encontros teve como base o recurso teórico-metodológico dos Círculos de Cultura de Paulo Freire.

1. Recuperado de: $<$ http://www.pmf.sc .gov.br/entidades/s aude/index.php?cm $\mathrm{s}=$ populacao\&menu $=0>$. Acesso em: ago. 2012.

2. Recuperado de: $<$ http://cstapera.blogspot.co m.br/>. Acesso em: mar. 2013.
O PET Saúde/SF, assim como o PET Saúde do qual faz parte, tem a educação pelo trabalho como pressuposto. Ambos os programas caracterizam-se como instrumentos para a qualificação dos profissionais de saúde e iniciação ao trabalho dos estudantes de graduação e estão instituídos no âmbito dos Ministérios da Saúde e da Educação. Os objetivos dos programas são comuns, sendo que o PET Saúde/SF destina-se, mais especificamente, ao fomento e articulação entre ensino e serviço na Estratégia Saúde da Família (ESF) por meio de grupos de aprendizagem tutorial formados por tutores, preceptores e estudantes-monitores. Esses grupos têm diversas atribuições, dentre elas a de produzir conhecimentos relevantes na Atenção Básica $(\mathrm{AB})$ e relacionados às atividades desenvolvidas no contexto do programa. Espe- ra-se, ainda, que façam referência à condição de bolsistas nas publicações e trabalhos apresentados (Portaria Interministerial no 421, Portaria Interministerial no 422, \& Portaria conjunta no 2).

O psicólogo - assim como os assistentes sociais, farmacêuticos, fisioterapeutas, fonoaudiólogos, profissionais da educação física, nutricionistas, terapeutas ocupacionais e médicos ginecologistas, homeopatas, acupunturistas, pediatras e psiquiatras - está inserido na $\mathrm{AB}$ por meio dos Núcleos de Apoio à Saúde da Família (NASF), criados em 2008 com o objetivo de

apoiar a inserção da Estratégia de Saúde da Família na rede de serviços, além de ampliar a abrangência e o escopo das ações da Atenção Básica e aumentar a resolutividade dela, reforçando os processos de territorialização e regionalização em saúde. (Brasil, 2009, p. 10)

Os Centros de Saúde (CS) representam a $A B$ como porta de entrada do Sistema Único de Saúde (SUS). Nesses, equipes de saúde da família operacionalizam a ESF e são responsáveis por um número definido de pessoas até 4 mil - que residem no território delimitado para atendimento pelo CS.

O CS no qual se realizou a atividade ora relatada em parceria com a creche atende a uma população estimada em 11.442 habitantes ${ }^{1}$. Nele, estão alocadas quatro equipes de SF e duas equipes de saúde bucal, além da equipe $\mathrm{NASF}^{2}$. Em março de 2011, esse CS contava, por meio do PET Saúde/SF, com estudantes-monitores nas áreas de Enfermagem (2) e Odontologia (2). Estes, juntamente com os preceptores e a tutora desse grupo, definiram como prioridade o trabalho com crianças em idade pré-escolar, dando continuidade ao trabalho iniciado em 2010 na creche. Em julho de 2011, quando os estudantes-monitores da Psicologia (3) foram vinculados ao CS, já estavam definidas as demandas de trabalho para essa área. Segundo o grupo que já estava atuando junto à creche, 
3. O PSE é um programa interministerial (Ministério da Saúde e Ministério da Educação). havia solicitação, por parte das educadoras, de maiores esclarecimentos quanto aos temas bullying e sexualidade infantil.

No primeiro contato com a diretora e com algumas das educadoras da creche, percebeu-se que a maior demanda dos profissionais estava relacionada ao tema sexualidade infantil. Quanto ao tema bullying, tratava-se de uma demanda relatada à equipe de saúde devido a um episódio específico que já havia sido encaminhado. A partir dessa constatação, propôs-se às presentes iniciar o trabalho com as questões relativas à sexualidade infantil. Entende-se que instrumentalizar professores de uma creche a compreender as expressões relacionadas à sexualidade como inerentes ao desenvolvimento das crianças pode contribuir para o rompimento do processo de patologização dessas expressões e, consequentemente, para a promoção de saúde dessas crianças e dos educadores (Yared, 2011).

Documentos oficiais, como os Parâmetros Curriculares Nacionais - PCN (Brasil, 1997), reconhecem que o tema sexualidade deve ser trabalhado na escola. A política do Programa Saúde na Escola - PSE $(2007)^{3}$ também reitera a importância de se abordar a questão no processo de formação de professores para que estes sejam instrumentalizados a lidar com as questões relativas à sexualidade no âmbito escolar.

Na proposta desenvolvida, compreendeu-se que a formação de educadores em sexualidade deve abranger o sujeito na sua totalidade, o modo como ele pensa, sente e age. Em conformidade com Gesser, Oltramari, Cord e Nuernberg (2012), entende-se que a contribuição de uma formação éticopolítica voltada a essa temática não deve se restringir à instrumentalização cognitiva dos educadores, mas contribuir também para que estes recriem o modo como lidam com as expressões da sexualidade que emergem no cotidiano escolar. Os autores afirmam ainda que o êxito do trabalho de formação de professores implica que este seja baseado nas dificuldades, nem sempre explícitas, enfrentadas no cotidiano do espaço escolar, ou seja, com objetivos definidos a posteriori (Freitas, 1998) e em serviço (Leão, Ribeiro, \& Bedin, 2010). A formação de educadores deve considerar também que o modo como esses sujeitos lidam com a sexualidade está relacionado aos discursos que permeiam o contexto no qual se constituíram, preponderantemente influenciado por concepções biomédicas ou morais e religiosas acerca da sexualidade (Yared, 2011).

Adotou-se, para orientação do desenvolvimento deste trabalho, o conceito de sexualidade proposto pela cartilha Gênero e Diversidade na Escola (Brasil, 2009). A opção ocorreu pelo fato de esse documento subsidiar uma política pública intersetorial, composta pelas seguintes secretarias: Secretaria Especial de Políticas para Mulheres da Presidência da República (SPM); Secretaria Especial de Direitos Humanos (SEDH); Secretaria de Educação Continuada, Alfabetização e Diversidade (Secad) e Secretaria Especial de Políticas de Promoção da Igualdade Racial (Seppir). De acordo com a cartilha:

As definições atuais da sexualidade abarcam, nas ciências sociais, significados, ideais, desejos, sensações, emoções, experiências, condutas, proibições, modelos e fantasias que são configurados de modos diversos em diferentes contextos sociais e períodos históricos. Tratase, portanto, de um conceito dinâmico que vai evolucionando e que está sujeito a diversos usos, múltiplas e contraditórias interpretações, e que se encontra sujeito a debates e a disputas políticas. Refere-se às elaborações culturais sobre os prazeres e os intercâmbios sociais e corporais que compreendem desde o erotismo, o desejo e o afeto, até noções relativas à saúde, à reprodução, ao uso de tecnologias e ao exercício do poder na sociedade. (Brasil, 2009, p. 112)

Não só o conceito de sexualidade mas toda a proposta do Programa de Formação de Professores "Gênero e Diversidade na Escola" (Brasil, 2009) apontam a sexualidade como 
algo inerente à condição humana. Além disso, ressalta a complexidade da temática, subsidiando a criação de estratégias de intervenção emancipadoras de todos os sujeitos nessa dimensão da vida.

A Educação Popular também foi um dos pressupostos deste trabalho. Ela se refere a uma estratégia política e metodológica adotada pelo Ministério da Saúde, embasando a Educação Popular em Saúde. Essa proposta denota a importância de que todas as práticas educativas desenvolvidas no âmbito do SUS impulsionem "movimentos voltados para a promoção da participação social no processo de formulação e gestão das políticas públicas de saúde, direcionando-as para o cumprimento efetivo das diretrizes e dos princípios do SUS: universalidade, integralidade, eqüidade, descentralização, participação e controle social" (Brasil, 2007, p. 16).

A seguir, explicitar-se-á a construção do percurso metodológico realizado no decorrer dos encontros. Na sequência, serão apresentados os principais resultados e, por fim, algumas considerações finais.

\section{Percurso metodológico}

Conforme brevemente explicitado na introdução deste artigo, o trabalho foi realizado em uma creche vinculada ao CS no qual ocorreu o PET Saúde/SF. Após um levantamento de necessidades realizado junto a profissionais da creche, foi constatado que havia demanda pela temática relacionada à sexualidade infantil. Esses assuntos foram encaminhados aos estudantes-monitores de Psicologia quando estes se juntaram à equipe do PET.

Após a inserção desses estudantes, foi realizada uma escuta com o intuito de refinar a demanda. A partir desta, ficou evidente que as dificuldades que mais mobilizavam os educadores naquele momento se referiam às expressões de sexualidade que ocorriam no cotidiano de trabalho desses profissionais.
As principais dificuldades relatadas pelos profissionais da creche estavam relacionadas tanto ao modo como eles poderiam lidar com as expressões de sexualidade advindas das crianças quanto aos questionamentos que os pais faziam sobre esse assunto. Também se percebeu que algumas professoras apresentavam um julgamento moral no que se refere aos gostos, de algumas crianças e demais pessoas da comunidade na qual a creche estava inserida, por músicas do estilo funk que, na opinião delas, contribuía para a erotização precoce das crianças. Por fim, identificou-se que as educadoras da creche percebiam as crianças como seres assexuados e demonstravam grande dificuldade para lidar com as expressões da sexualidade infantil quando essas apareciam no cotidiano da escola.

Destaca-se que esse refinamento da demanda, por meio da escuta das educadoras, é consonante com os pressupostos da Educação Popular e vai ao encontro do preconizado por Freitas (1998), a qual afirma que os trabalhos no âmbito comunitário devem ser orientados pelas necessidades da comunidade. Outra preocupação levada em consideração no desenvolvimento das atividades foi a de incluir todos os atores sociais, tanto na caracterização da demanda quanto no planejamento das ações e na avaliação destas. Dessa forma, os objetivos norteadores deste trabalho foram definidos a posteriori.

Os encontros promovidos para os educadores da creche foram coordenados por três acadêmicos do curso de Psicologia da UFSC, todos monitores do PET Saúde/SF. Foram realizados sete encontros, o primeiro com duas horas e meia de duração e os subsequentes com cerca de uma hora e meia de duração cada, quinzenalmente, durante o segundo semestre de 2011. Participaram dos encontros nove educadoras com idades entre 25 e 47 anos, sendo três professoras, cinco auxiliares de sala e a diretora da creche. Destas, seis eram pós-graduadas, uma possuía nível superior completo, uma nível superior incompleto e uma havia cursado o magistério. 
Em consonância com a Educação Popular em Saúde, utilizaram-se os Círculos de Cultura de Paulo Freire como recurso teórico-metodológico para o desenvolvimento das atividades. Estes podem ser definidos "como um espaço dinâmico e horizontal de aprendizagem, onde os sujeitos participantes investigam questões que lhes são significativas, problematizando situações da sua própria vivência de mundo" (Simão, Zurba, \& Nunes, 2012, p.85).

A Educação Popular é baseada no diálogo. Neste, os participantes se reconhecem mutuamente e colaboram entre si. Assim considerado, não há hierarquia entre educador e educando, ambos são sujeitos do processo ao educarem-se enquanto mediatizados pelo mundo (Freire, 1987). No entanto, entende-se que a horizontalidade dessa relação não implica a omissão do saber por parte daqueles que o detêm; esse deve ser disponibilizado para que possa ser constituinte do processo educativo. Outro pressuposto que se buscou preservar neste trabalho foi o caráter político da Educação Popular. Para Simão et al. (2012, p. 90), é considerada intervenção política "a ação em que o sujeito reflete criticamente sobre a produção de sua realidade e a partir dela transforma sua relação com a produção dessa realidade". Para tanto, o exercício de reflexão crítica foi estimulado durante todo o processo e foi incentivada a construção de uma proposta de trabalho que pudesse materializar os conteúdos trabalhados durante os encontros.

Antes do início do trabalho na creche, os estudantes-monitores de Psicologia participaram de uma série de encontros de formação durante os quais foram efetuados leituras, discussões e compartilhamento de conhecimentos sobre o trabalho no SUS e Educação Popular em Saúde, bem como Círculos de Cultura. A formação, organizada por acadêmicos do curso de Psicologia da UFSC, foi realizada no formato de Círculo de Cultura, com o intuito de se treinar o papel de coordenador e de vivenciar o de participante nesse tipo de atividade. Dessa forma, foi possível o esclareci- mento de dúvidas, a experimentação da metodologia e, a partir dessa experiência, o planejamento das atividades que seriam desenvolvidas na creche.

O trabalho foi desenhado a partir de temas geradores, conforme estes iam surgindo ao longo dos encontros, de acordo com os pressupostos da Educação Popular. Esses temas, obrigatoriamente, deviam ser eleitos pelo grupo e, por este, considerados relevantes. Os temas geradores foram compreendidos pelos coordenadores como demonstrativos do conhecimento prévio e dos significados atribuídos pelos participantes às questões levantadas, o que possibilitou um melhor contato com a realidade dos educadores e favoreceu o diálogo.

Cada um dos encontros foi estruturado basicamente em três momentos: aquecimento, atividade principal e compartilhamento, análogos às etapas do método psicodramático, que são aquecimento, dramatização e compartilhamento (Holmes \& Karp, 1992; Bustos, 2005). Para o aquecimento e a atividade principal, foram utilizadas diferentes estratégias teórico-metodológicas como mediadoras para a discussão dos temas. Essas estratégias foram adaptadas de acordo com as características e demandas do grupo e a partir de diferentes jogos dramáticos, com o objetivo de favorecer o engajamento dos participantes à atividade, além de fazer emergir temas a serem trabaIhados durante o encontro (Yozo, 1996). O compartilhamento incluía a reflexão sobre o trabalho realizado, a sintetização dos principais pontos pelos coordenadores e a escolha, pelo grupo, do tema para o próximo encontro.

O primeiro encontro, diferentemente dos demais, foi realizado durante a parada pedagógica, sendo, portanto, acessível a todos os educadores e auxiliares de classe da creche. Contou com a participação de 23 funcionários e teve duas horas e meia de duração. Visando conhecer melhor os participantes e suas significações em relação à sexualidade, foi solicitado, durante o primeiro momento do encontro, que cada um dissesse 
seu nome e a primeira palavra que havia pensado ao ouvir o termo sexualidade. Essas palavras foram anotadas em papel pardo e foram utilizadas tanto como subsídios para nortear os encontros seguintes como também, ao final do trabalho com o grupo, para avaliar os resultados obtidos. Em seguida, dividiu-se os participantes em quatro pequenos grupos e, nestes, discutiu-se sobre as brincadeiras sexuais das quais participavam na infância. No terceiro momento, os grupos apresentaram o que havia sido discutido e daí vieram as primeiras sugestões de temas para os próximos encontros. As principais questões referiam-se a como lidar com as crianças que apresentam comportamento sexual considerado inadequado, como nomear corretamente os órgãos genitais, qual a influência das letras e coreografias dos funks atuais no desenvolvimento das crianças, como conversar com os pais sobre os assuntos relacionados à sexualidade, entre outras.

No segundo encontro, foram distribuídas afirmações relacionadas à sexualidade e ao desenvolvimento infantil para que os participantes dissessem se concordavam ou não com elas. Essa atividade permitiu aos coordenadores conhecerem mais a respeito das concepções de sexualidade que permeavam o grupo. No momento seguinte, os participantes foram divididos em pequenos grupos e procederam à leitura de um material sobre o tema. Em seguida, discutiram experiências de sala de aula à luz do texto lido e relataram experiências pessoais da infância. Discutiuse ainda sobre como a curiosidade sexual da criança está relacionada ao seu desenvolvimento e processo de aprendizagem, e os tabus que permeiam o olhar do adulto diante de tais questões. O tema escolhido pelo grupo para o encontro seguinte foi "COmunicação com a família das crianças".

No terceiro encontro, solicitou-se aos participantes, divididos em dois grupos, que compartilhassem cenas, reais ou imaginárias, relacionadas à sexualidade dos alunos sobre as quais teriam maior constrangimento de conversar com os pais. Os grupos discutiram e, então, pediu-se que escolhessem a cena que melhor representasse a apreensão do grupo para ser representada. Nesse encontro, houve tempo para uma representação apenas, sendo esta a de uma cena real que havia ocorrido na creche e que os educadores tiveram muita dificuldade para representar, visto que sua ocorrência acarretou brigas e teve um desfecho indesejável. A partir da cena escolhida, as participantes levantaram pontos como o lugar adequado para conversar com os pais, a importância do cuidado na escolha dos termos empregados nesse diálogo, a necessidade de conversarem entre si e com a diretora para juntas construírem o procedimento a ser adotado. Também se conversou sobre a angústia que os pais sentem ao discutir questões referentes à sexualidade de seus filhos e o papel das educadoras nesses momentos. Ficou combinado que o próximo encontro seria iniciado pelo segundo grupo.

O quarto encontro tinha a proposta de dar continuidade ao exercício de dramatizar cenas que envolvessem familiares dos alunos em comunicações sobre eventos relativos à sexualidade ocorridos no contexto da sala de aula. A cena foi apresentada e a participante que fez o papel da educadora mostrou-se ansiosa ao tentar explicar para a "mãe" o que ela havia observado quanto ao comportamento da criança e não conseguiu transmitir a mensagem. O grupo levantou diversos pontos para discussão: quanto à linguagem, quanto à ansiedade, quanto ao foco da mensagem a ser transmitida e quanto aos motivos que fazem com que seja tão difícil falar sobre sexualidade na infância.

Pautadas na técnica psicodramática da tomada de papel, que consiste na assunção do papel de um personagem, o que proporciona ao indivíduo a possibilidade de entrar em contato com outras formas de pensar, sentir e perceber situações (Dias, 1996), as dramatizações realizadas pelos professores evidenciaram o quanto mitos e preconceitos relacionados à sexualidade infantil, que consideram as crianças como seres assexuados, estavam presentes 
e eram elementos mediadores do modo como eles lidavam com as expressões da sexualidade infantil. Partindo-se do pressuposto da indissociabilidade entre as dimensões do pensar, sentir e agir, esses foram problematizados a partir da historicidade. Ou seja, buscou-se resgatar a construção da noção de infância e os discursos que reduzem a sexualidade ao coito pênis-vagina e a associam à idade adulta e à reprodução. Ficou definido que, no próximo encontro, seriam discutidas mídia e erotização infantil, ainda com o propósito de que os professores pudessem ter melhor entendimento, reflexão e capacidade de lidar com o assunto nas diversas situações em que são demandados.

A proposta do quinto encontro foi debater sobre a polêmica da erotização nas músicas de funk por meio do texto "Mulher, mídia e movimentos culturais" de Feghali (2001).. Para tanto, foram sorteadas as posições que cada participante teria no debate (a favor, contra ou mediação) e distribuído o texto em questão. O motivo da utilização dessa estratégia é o de que ela favorece a percepção da alteridade, ou seja, de que nas relações sociais (interpsicológicas), os sujeitos se constituem e se diferenciam uns dos outros (Zanella, 2005).

O grupo que foi sorteado para defender o funk mostrou-se desconfortável no início, visto que estava representando uma posição com a qual não concordava. Após breve debate realizado pelos integrantes de cada grupo, iniciou-se a discussão. Notou-se que as participantes do grupo contrário ao funk argumentaram sem sair do seu papel de educadoras; o grupo favorável, no entanto, assumiu o papel da família dos alunos. Ao assumirem o papel das famílias, as educadoras puderam empatizar com o significado que o funk tem na vida dessas pessoas, colocandose em uma relação de alteridade no que se refere a essa questão. Além disso, as educadoras se surpreenderam com a sua performance e afirmaram sentir-se mais sensíveis em relação às famílias da comunidade. As integrantes do grupo contrário afirmaram que teriam de rever suas posições, visto que há mais de um ponto de vista possível com relação a esse tema. Uma das educadoras desse grupo defendeu que é necessário que a escola não se preste apenas a criticar o que considera inapropriado, mas que propicie aos alunos o contato com formas alternativas de cultura além daquelas às quais eles já têm acesso. Percebeu-se que essa atividade propiciou um estranhamento com o que estava naturalizado, evidenciando o potencial de reflexão e transformação produzido por ela.

Considerando que o sexto encontro seria o penúltimo, optou-se por retomar alguns pontos e iniciar o processo de fechamento e avaliação do trabalho. Diante disso, foi proposto às educadoras que dissessem a primeira palavra que pensassem ao ouvir o termo sexualidade. Discutiu-se que as palavras escoIhidas pelos educadores nesse encontro estavam mais relacionadas ao cotidiano profissional, ao papel do educador na orientação sexual dos alunos no contexto escolar, que aquelas utilizadas para a confecção do cartaz realizado no primeiro encontro. Após essa discussão, foi resgatada a proposta, feita por alguns educadores nos encontros anteriores, de convidar os pais no início do ano letivo para dialogar sobre a sexualidade na infância, já que eles avaliaram que dessa forma a escola poderia auxiliar os pais em suas questões sobre como lidar com as curiosidades e vivências dos filhos sobre a sexualidade.

O sétimo encontro - e último dessa formação - teve como proposta a elaboração de projetos de intervenção no espaço escolar a partir dos conhecimentos e reflexões realizados no transcorrer dos encontros sobre sexualidade infantil. Todos deveriam conter objetivos e um plano de execução. Para tanto, foram organizados três grupos de educadoras e cada um deles apresentou um projeto diferente, porém complementares. O primeiro grupo propôs um trabalho com todos os educadores da creche com o objetivo de difundir, por meio de atividades diversas, os conhecimentos relacionados à sexualidade 
infantil adquiridos e vivenciados durante a formação. O segundo e o terceiro grupos elaboraram propostas de trabalho voltadas aos pais dos alunos. Um deles propôs a inclusão, na ficha de identificação da criança que é preenchida no início do ano, de um espaço de preenchimento opcional no qual os pais pudessem expor suas dúvidas ou sugerir temas sobre sexualidade infantil e outros assuntos. Dessa forma, seria possível fazer um levantamento das dúvidas e, então, buscar formas de esclarecê-las. O último grupo sugeriu a montagem de uma peça de teatro que abordasse a temática da sexualidade infantil seguida de uma roda de conversa com os pais para que esses pudessem fazer seus questionamentos. O terceiro grupo incluiu em sua proposta a participação de todos os funcionários da creche, não só educadores ou auxiliares de classe, tanto como atores da peça quanto na discussão sobre os temas que seriam contemplados.

Após a apresentação das propostas, discutiu-se sobre a importância do envolvimento de todos os educadores na temática sexualidade infantil antes de se trabalhar visando ao acolhimento dos pais, o que poderia ser feito de acordo com o primeiro projeto. $\mathrm{O}$ encontro foi finalizado com a apresentação, pelos coordenadores, de um esquema contendo todas as questões discutidas nos seis encontros anteriores, como uma forma de sintetização e materialização dos conceitos, reflexões, dúvidas e propostas que surgiram nesse processo.

\section{Resultados e Discussão}

A necessidade de realização deste trabalho surgiu a partir de inúmeras dificuldades que os educadores da creche tinham em lidar com as expressões de sexualidade infantil que emergiam no cotidiano da sala de aula. Essas dificuldades podem ser explicadas, de acordo com Leão (2009) e Silva (2010), como decorrentes de esses temas não serem oferecidos na formação inicial e continuada de professores de forma sistemática. Os au- tores destacam que, quando emergem nesses espaços, são abordados de forma espontaneísta e sem um caráter histórico crítico, desencadeando a repetição desse modelo em suas práticas cotidianas.

O trabalho ora apresentado propôs-se, a partir das necessidades identificadas junto aos educadores, a promover um espaço de discussão e reflexão voltado ao aprofundamento da temática sexualidade de acordo com as questões que eles vivenciavam no cotidiano da sala de aula. Os resultados obtidos, a partir da avaliação da experiência, evidenciaram que ocorreu a ressignificação do modo como os educadores se relacionavam com as expressões da sexualidade na infância.

Em avaliação realizada antes do período das oficinas, constatou-se que as educadoras da creche se sentiam despreparadas para lidar com o tema da sexualidade infantil e, em consequência, acabavam por desconsiderar ou até repreender muitas das expressões que surgiam no cotidiano da sala de aula. Esse dado foi identificado também no estudo realizado por Costa (2009) junto a profissionais da educação. Por outro lado, havia uma preocupação, por parte das educadoras da creche, com o respeito à curiosidade sexual manifestada pelas crianças como inerente ao seu processo de desenvolvimento, o que evidencia um compromisso ético-político delas.

A partir do trabalho realizado, as educadoras conseguiram produzir novas significações referentes às expressões de sexualidade na infância, passando a percebê-las como inerentes ao processo de desenvolvimento das crianças. Esse resultado é bem significativo, haja vista que, a partir dessa mudança de olhar sobre esse fenômeno, é possível evitar a patologização das expressões de sexualidade infantil que, muitas vezes, são interpretadas como distúrbio ou até perversão infantil (Santa Catarina, 2008). A reprodução de mitos relacionados à sexualidade nas práticas educativas infantis pode ser um elemento obstaculizador 
do desenvolvimento da criança na dimensão da sexualidade. O fornecimento de informações incorretas ou simplesmente a dificuldade de o educador tocar no assunto pode dificultar o processo de identificação de situações de abuso sexual e demais violências no campo dos direitos sexuais e reprodutivos.

O tema da violência sexual infantil suscitou questionamentos diversos por parte das educadoras. Após discussões sobre o tema, nas quais foram abordadas as formas e a identificação de situações de violência sexual, concluiu-se que a creche, ao assumir o seu papel na educação sexual das crianças, contribui, principalmente, com um trabalho de prevenção da violência. Como já afirmado por Silva, Souza e Santos (2007), a prevenção, realizada por meio de orientação, informação e sensibilização de todos os atores sociais, "é a melhor forma de evitar as várias formas de violência sexual" (p. 101). As educadoras ressignificaram ainda o preconceito em relação a músicas e modos de lidar com a sexualidade diferentes do padrão naturalizado por elas. A partir da atividade realizada no quinto encontro, elas também realizaram reflexões importantes sobre o papel das instituições de ensino de, sem desqualificar os gostos dos alunos e suas famílias, disponibilizarem novas possibilidades culturais e informativas.

Considera-se ainda que uma das contribuições desse trabalho foi o reconhecimento, por parte das educadoras, de que a creche tem um papel importante em relação à família de seus alunos. Ao se sentirem melhor preparadas e, consequentemente, mais seguras com relação ao tema da sexualidade infantil, as educadoras perceberam que podem acoIher as angústias familiares oriundas das expressões de sexualidade das crianças. Entenderam também que podem contribuir orientando as famílias, por meio de ações de esclarecimento pontuais ou amplas, com relação às expressões da sexualidade que ocorrem, de diferentes formas e intensidades, no decorrer do desenvolvimento infantil.
Durante e no fim do trabalho realizado, destacou-se o reconhecimento das participantes do grupo quanto à importância de discutir as questões relacionadas à sexualidade integradas ao desenvolvimento infantil. Além disso, como foi evidenciado nas propostas construídas no último encontro, as próprias educadoras identificaram a necessidade de o trabalho ser realizado com todos os atores sociais da creche e desde um ponto de vista que entenda a sexualidade a partir de uma perspectiva biopsicossocial, rompendo assim com discursos morais, religiosos e biomédicos, reproduzidos cotidianamente nas práticas educativas (Gesser et al., 2012; Yared, 2011).

Essa postura vai ao encontro do que propõem os PCN (Brasil, 1998), bem como o PSE, que dão ao educador um lugar central no trabalho de educação sexual no âmbito da escola. Segundo os PCN (Brasil, 1998), os educadores devem se mostrar disponíveis para esclarecer questões referentes à sexualidade, problematizar e debater as diferentes noções de sexualidade presentes na sociedade, assim como os preconceitos a elas relacionados e reconhecer, na busca do prazer e curiosidades manifestadas pelas crianças e adolescentes, a legitimidade inerente a essa dimensão do processo de desenvolvimento.

A utilização dos Círculos de Cultura propiciou a problematização dos diversos aspectos relatados a partir do repertório de conhecimentos prévios dos educadores em articulação com o conhecimento científico atualizado e pesquisado para atender aos objetivos definidos no decorrer do trabalho. Em consonância com o preconizado por Freire (1996), a escuta e consideração dos conhecimentos prévios, resultantes da "pura experiência", foram necessárias para a superação do senso comum e estimulação da capacidade criadora dos educadores. Além disso, a compreensão do papel político que os educadores assumem perante as crianças e famílias ao incluírem essa importante dimensão do desenvolvimento infantil os potencializa a descobrirem diferentes formas de educar. 
Conforme a proposta de formação de professores "pautada em uma perspectiva éticopolítica de sexualidade e de educação inclusiva" apresentada por Gesser et al. (2012), o processo foi norteado pela compreensão de que a sexualidade deve ser entendida como integrada à vida. Para tanto, levou-se em conta a "totalidade de dimensões constitutivas do sujeito" por meio da disponibilização de um espaço que possibilitasse a reflexão sobre o tema e a revisão de valores, sentimentos, tabus e preconceitos pessoais em relação à sexualidade (Figueiró, 2009). A partir da potencialização das discussões e reflexões, foi possível a construção de propostas e estratégias relacionadas às dificuldades cotidianamente vivenciadas pelas educadoras.

\section{Considerações finais}

A formação de professores em sexualidade infantil é uma das diversas possibilidades de atuação de psicólogos no contexto escolar. A particularidade dessa formação, desenvolvida a partir do vínculo da creche com o CS, permitiu que desde a entrada na instituição os estudantes-monitores da Psicologia pudessem propor um trabalho com foco na prevenção e promoção da saúde. Entendese que essa característica da experiência foi essencial para que a expectativa dos educadores fosse diferente daquela historicamente relacionada à Psicologia no âmbito escolar: o foco no problema oriundo do aluno ou de suas famílias.

Os pressupostos teórico-metodológicos dos Círculos de Cultura pautados em Paulo Freire (Simão et al., 2012) propiciaram uma prática de educação alternativa àquelas tradicionalmente utilizadas nas formações de educadores. Estes, ao serem incluídos na construção do processo, tornaram-se corresponsáveis pelos resultados obtidos no mesmo e puderam constatar a importância de sua implicação para a revisão de suas posturas quanto ao tema da sexualidade. Além disso, a utilização de estratégias metodológicas grupais, como dramatizações, colagens, discussão de pequenos textos e construção de projetos de intervenção baseados na realidade da creche, por serem subversivas em relação à lógica bancária (Freire, 1987) de formação de educadores, mostrou-se eficaz para se atingir o objetivo do trabalho.

Entende-se que os efeitos desse trabalho sejam de difícil mensuração e que um acompanhamento da implementação dos projetos construídos pelos educadores seria necessário, o que não foi possível. Verificou-se, entretanto, que ocorreu uma desestabilização dos conceitos relativos à sexualidade infantil, o que pôde abrir espaço para a apropriação de novos olhares que vão contribuir de diferentes formas para a construção de novas práticas relacionadas ao tema.

A experiência possibilitou aos estudantesmonitores a oportunidade de integração entre o aprendizado da sala de aula e a realidade de trabalho de seu campo profissional. Além disso, experimentou-se tanto o contato com a estratégia baseada no Círculo de Cultura quanto o relacionamento com diferentes atores com os quais um profissional da saúde pública lida no seu cotidiano de trabalho. $\mathrm{O}$ contato com esses atores incitou uma intensa reflexão sobre as variadas práticas e visões dos profissionais de diferentes campos da saúde que trabalham conjuntamente e as dificuldades daí decorrentes.

A experiência proporcionou ainda a aquisição de conhecimentos sobre o sistema de saúde, em especial sobre a importância do trabalho territorializado e em rede. Considera-se que a inserção de graduandos da Psicologia no PET Saúde/SF pode contribuir para a mudança do perfil desses futuros profissionais a partir da repercussão que as vivências práticas provocam nos alunos e que estes, consequentemente, provocam nas instituições formadoras às quais estão vinculados. 


\section{Adriane Costa e Rocha Ciaffone,}

Psicóloga cursando especialização em Terapia Relacional Sistêmica no Instituto Familiare, Florianópolis - SC e Psicóloga clínica em consultório particular. E-mail: arciaffone@gmail.com.

\section{Marivete Gesser,}

Doutora em Psicologia pela Universidade Federal de Santa Catarina e Professora da Graduação e do Programa de Pós-Graduação emPsicologia da Universidade Federal de Santa Catarina.

E-mail: marivete@yahoo.com.br

Endereçopara envio de correspondência:

Rua Rosa, 119, apto 301, Pantanal, Florianópolis, SC, 88040-270

Recebido 09/03/2013, 1a Reformulação 15/01/2014 Aprovado 04/08/2014. 


\section{Referências}

Brasil, Ministério da Educação. Secretaria de Educação Fundamental. (1997). Parâmetros Curriculares Nacionais: pluralidade cultural/orientação sexual. Brasília, DF: Autor

Brasil, Ministério da Saúde (2007). Cadernos de Educação Popular e Saúde. Brasília, DF: Autor.

Brasil, Presidência da República. (2007). Decreto presidencial e interministerial n. 6.286 de 5 de dezembro de 2007. Institui o Programa Saúde na Escola. Brasília, DF: Diário Oficial da União, seção I.

Brasil, Ministério da Saúde (2009). Cadernos de Atenção Básica: Diretrizes do NASF Núcleo de Apoio a Saúde da Família. Brasília, DF.

Brasil, Secretaria de Políticas para as Mulheres. (2009). Gênero e diversidade na escola: formação de professoras/es em Gênero, Orientação Sexual e Relações Étnico-Raciais. Rio de Janeiro: CEPESC; Brasília: SPM.

Bustos, D. M. (2005). Psicodrama: aplicações da técnica psicodramática. São Paulo: Ágora.

Centro de Saúde da Tapera. (2013). Serviços. Recuperado em 12 março, 2013, de http://cstapera.blogspot.com.br/p/servicos.html.

Costa, A. P. (2009). As concepções de sexualidade de um grupo de alunas do curso de Pedagogia: uma análise a partir do recorte de gênero. Dissertação de Mestrado, Universidade Estadual Paulista, Araraquara, SP.

Dias, V. R. C. da S. (1996). Sonhos e psicodrama interno na análise psicodramática. São Paulo: Ágora.

Feghali, J. (2001). Mulher, mídia e movimentos culturais. Presença da Mulher, 39(1), pp. 1922. Recuperado em 19 agosto, 2012, de http://www.cpvsp.org.br/upload/periodicos/p df/PPREMSP072001039.pdf.

Figueiró, M. N. D. (2009). Educação Sexual: como ensinar no espaço da escola. In M. N. D. Figueiró (Org.), Educação sexual: múltiplos temas, compromissos comuns (pp. 141-171). Londrina, PR: UEL.

Freire, P. (1987). Pedagogia do oprimido. Rio de Janeiro: Paz e Terra.

Freire, P. (1996). Pedagogia da autonomia: saberes necessários à prática educativa. São Paulo: Paz e Terra.
Freitas, M. F. Q. (1998). Inserção na comunidade e análise de necessidades: reflexões sobre a prática do psicólogo. Psicologia: Reflexão e Crítica 11(1), 175-189. doi http://dx.doi.org/ 10.1590/S0102-79721998000100011.

Gesser, M., Oltramari, L. C., Cord, D., \& Nuernberg, A. H. (2012). Psicologia Escolar e formação continuada de professores em gênero e sexualidade. Psicol. Esc. Educ., 16(2), 229236. doi: http://dx.doi.org/10.1590/S141385572012000200005

Holmes, P., \& Karp, M. (1992). Psicodrama Inspiração e Técnica. São Paulo: Ágora.

Leão, A. M. C. (2009). Estudo analítico-descritivo do curso de Pedagogia da Unesp-Araraquara nas temáticas de sexualidade e orientação sexual na formação de seus alunos. Tese de Doutorado, Universidade Estadual Paulista, Araraquara, SP.

Leão, A. M. C., Ribeiro, P. R. M., \& Bedin, R. C. (2010). Sexualidade e orientação sexual na escola em foco: algumas reflexões sobre a formação dos professores. Linhas. 11(1), 3652.

Prefeitura Municipal de Florianópolis - PMF. (2012). População Florianópolis 2012. Recuperado de http://www.pmf.sc.gov.br/ e $\mathrm{nt}$ i d a d e s/s a u d e/ i n d e x . php?cms $=$ populacao\&menu $=0$

Portaria conjunta n. 2 (2010, 03 de março). Institui no âmbito do Programa de Educação pelo Trabalho para a Saúde (PET Saúde), o PET Saúde/Saúde da Família. Diário Oficial da União, seção 1.

Portaria interministerial n. 421 (2010, 03 de março). Institui o Programa de Educação pelo Trabalho para a Saúde (PET Saúde) e dá outras providências. Diário Oficial da União, seção 1.

Portaria interministerial n. 422 (2010, 03 de março). Estabelece orientações e diretrizes técnico-administrativas para a execução do Programa de Educação pelo Trabalho para a Saúde - PET Saúde, instituído no âmbito do Ministério da Saúde e do Ministério da Educação. Diário Oficial da União, seção 1.

Santa Catarina. Secretaria de Estado da Educação. (2008). Proposta curricular de Santa Catarina. Santa Catarina: SEE. 
Silva, M. C. P. da, Souza, P. O. de, \& Santos, Z. dos (2007). Violência sexual infantil. In M. C. P. da Silva, (Org.), Sexualidade começa na infância (pp. 95-111). São Paulo: Casa do Psicólogo.

Silva, L. R. G. (2010). Sexualidade e orientação sexual na formação de professores: uma análise da política educacional. Tese de Doutorado, Universidade Estadual Paulista, Araraquara, SP.

Simão, C. R. P., Zurba, M. do C., \& Nunes, A. de S. B. (2012). Educação popular em saúde: o círculo de cultura como ferramenta de promoção de participação popular no SUS. In M. do C. Zurba (Org.), Psicologia e saúde coletiva (pp. 75-101). Florianópolis, SC: Tribo da Ilha.
Yared, Y. B. (2011). A educação sexual na escola: tensões e prazeres na prática pedagógica de professores de ciências e biologia. Dissertação de Mestrado, Universidade do Planalto Catarinense, Lages, SC.

Yozo, R. Y. K. (1996). 100 Jogos para Grupos: Uma abordagem psicodramática para empresas, escolas e clínicas. São Paulo: Ágora.

Zanella, A. V. (2005). Sujeito e alteridade: reflexões a partir da psicologia histórico-cultural. Psicologia \& Sociedade, 17(2), 99-104. doi: http://dx.doi.org/10.1590/S010271822005000200013 . 